\title{
Cultural Influences on Artificial Intelligence: Along the New Silk Road
}

\author{
Lynda Hardman
}

\begin{abstract}
Applications of AI, in particular data-driven decision-making, concern citizens, governments, and corporations. China was one of the first countries to have identified AI as a key technology in which to invest heavily and develop a national strategy. This in turn has led to many other countries and the European Union (EU) to develop their own strategies. The societal investments and applications of AI are so far-reaching that looking only at the resulting technological innovations is insufficient. Instead, we need to be aware of the societal implications of AI applications - of which there are many_as well as the geopolitical role of business and academic players.
\end{abstract}

\section{Artificial Intelligence in China}

While 20 years ago China was still learning from the international AI community, investments and policies have led to the current situation where China is rapidly overtaking the USA and EU in expertise in AI research, education, and innovation. China has ambitions to become a world leader in AI by 2030 (CISTP 2018), elevating the phrase "made in China" to a data-driven, hi-tech ecosystem for manufacturing goods and technology. China developed an AI strategy in the “China AI Development Report 2018" (CISTP 2018) in conjunction with partners representing both academic and commercial interests in the country, overseen by the

The opinions in this chapter are the author's own and do not necessarily reflect those of her employers or the organizations she represents. This chapter is based on the Amsterdam Data Science blog item "AI Research with China: to Collaborate or not to Collaborate - is that the Question?" and Hardman (2020). https://amsterdamdatascience.nl/ai-research-with-china-tocollaborate-or-not-to-collaborate-is-that-the-question/

\footnotetext{
L. Hardman ( $\square)$

CWI, Amsterdam, The Netherlands

University of Utrecht, Amsterdam, The Netherlands

e-mail: Lynda.Hardman@cwi.nl 
China Institute for Science and Technology Policy (CISTP) at Tsinghua University. Among the policy goals stated in the report are:

- To increase public awareness

- To promote the development of AI industry (to retail, agriculture, logistics, finance, and reshaping production, e.g.)

- To act as a reference for policy makers

Societal goals for the use of AI are:

- Helping with an aging population

- Supporting sustainable development

- Helping the country transform economically — toward China as hi-tech developer and supplier, rather than consumer

The first two of the societal goals are shared by Europe and the USA, leading to benefits in collaboration. The transformation of China to a hi-tech supplier is more likely to lead to competition, a valid endeavor in its own right, but results in global competition for talent.

The report is realistic about the Chinese context, stating "Even recognized domestic AI giants such as Baidu, Alibaba and Tencent (BAT) don't have an impressive performance in AI talent, papers and patents, while their U.S. competitors like IBM, Microsoft and Google lead AI companies worldwide in all indicators" (CISTP 2018, p. 6).

The executive summary concludes with "Currently, China's AI policy has emphasized on promoting AI technological development and industrial applications and hasn't given due attention to such issues as ethics and security regulation" (CISTP 2018, p. 7).

China takes a long-term view, and this can be seen in its investments in AI research and innovation, and particularly its tech talent. Huge efforts have been made to attract successful Chinese AI researchers back to their home country to continue their internationally competitive research and to educate new generations of talent. China's presence in the international AI research community is growing, as demonstrated by the increasing percentage of papers in the top international AI conferences that are co-authored by Chinese colleagues, working from China or from abroad (Elsevier 2018).

The CISTP report also observes that the priorities of the USA are economic growth, technological development, and national security (CISTP 2018, p. 5), whereas the concerns of Europe are the ethical risks caused by AI on issues such as security, privacy, and human dignity (CISTP 2018, p. 5). These different regional policies seem aligned with underlying cultural differences among the regions. 


\section{Artificial Intelligence in Europe}

The EU started developing national and European strategies around 2018, for example, establishing the European-wide High-Level Expert Group on Artificial Intelligence, ${ }^{1}$ which has produced Ethics Guidelines for Trustworthy AI and corresponding Policy and Investment Recommendations toward sustainability, growth, competitiveness, and inclusion (Craglia et al. 2018), and later publishing a Coordinated Plan on Artificial Intelligence. ${ }^{2}$ This drive for AI investment is probably also fueled by the huge investments in China, creating a "fear of losing out" if Europe is not able to remain competitive. The European investment drive is not solely from an economic perspective, as illustrated by the different aspects of the report, such as sustainability and inclusion.

Around the same time that the High-Level Expert Group was developing its report, many computer science academics and professionals were themselves concerned by the growing impact of AI technology and potential unintended negative implications. Informatics Europe and the ACM Europe Council published the joint report "When Computers Decide: European Recommendations on MachineLearned Automated Decision Making" 3 in February 2018. The report states the utility and dangers of decisions made by automated processes and provides recommendations for policy leaders.

\section{Cultural Differences in Applying Artificial Intelligence Technology}

While better, and more, researchers across the globe is generally good news for academic research, in AI we need to remain cautious. China's enormous investments in AI have led to domination in a narrow set of sub-fields around machine learning, with an emphasis on computer vision and language recognition. This domination could be perceived as cause for concern from an international standpoint. For example, computer vision techniques can be developed for facial recognition to track the movements of citizens. Different cultures perceive the benefits and dangers of these applications differently. Using these same techniques for other applications, such as distinguishing cancerous from benign cells, is, however, widely perceived as good.

The international community has closely aligned objectives in application areas of AI such as climate change, transport, energy transition, and the health and wellbeing of their aging citizens.

\footnotetext{
${ }^{1}$ https://ec.europa.eu/digital-single-market/en/high-level-expert-group-artificial-intelligence

${ }^{2}$ https://ec.europa.eu/knowledge4policy/publication/coordinated-plan-artificial-intelligencecom2018-795-final_en

${ }^{3}$ https://www.informatics-europe.org/component/phocadownload/category/10-reports.html? download=74:automated-decision-making-report
} 
This brings us to the difficult political and scientific choices that need to be made as to when and how to collaborate with China and when to politely decline. Do AI researchers need to completely halt all collaboration with Chinese academics and companies? Cessation of collaboration would be counter to the established international research culture of openness and dialogue.

European AI researchers are unlikely to want to work with Chinese colleagues on topics that may aid the Chinese state in actions that do not conform to European civil rights and values. That there is a cultural difference in the desirability ascribed to the trade-offs between privacy and security for those living in China and the West is hard to understand in and of itself and even harder when researchers are not familiar with the Chinese culture. AI researchers are not the most knowledgeable of global cultural differences, nor do many European researchers spend extended periods of time in China to learn first-hand.

Given the relatively small amount of research funding in European countries and from the European Union, the welcome addition of funds from abroad would seem like a golden opportunity. But things are not always as easy as they may appear. Firstly-do European AI researchers want to work with Chinese colleagues? Secondly-do European academic institutions want to be funded by Chinese companies?

It is currently more common for European researchers to collaborate with large US-based corporations. They fund research collaborations and attract high-profile staff to work with them. At the same time, they have created the data economy that led to the passing of EU law to give European citizens at least some control of the data that they (often unknowingly) hand over to these corporations. There is, to my knowledge, little discussion in my academic field as to whether we should think carefully about collaborations with these US-based companies.

\section{Artificial Intelligence Talent: Mobility and Global Competition}

We need highly educated AI practitioners to develop the wealth of useful/valuable applications across the globe. There is, however, an international shortage of AI talent, including machine learning and data analytics talent. All parts of the globe are looking to educate their own talent and to attract excellent talent from abroad. This requires investment in a number of ways, such as increasing the number of qualified academic staff and increasing the efficiency of teaching. Working for industry brings its own financial rewards. Tenured academic positions are attractive because of the opportunity to carry out research. This requires extended research funding, requiring either a larger slice of the available national (or, in Europe, European) funding or attracting more funding from companies. Companies across the globe are acutely aware of their shortage of talent and are willing to invest in academic research funding to maintain an active base of researchers and teachers in academia. Excellent researchers attract excellent young talent, and, given the English-language 
foundation of the AI and the computer science fields, the same talent can be attracted to China, Europe, or the USA.

There are, however, differences in the willingness of students to leave their continent to seek their fortune. It is likely that Chinese AI and computer science students will study for some time abroad before returning to China where research resources are currently (anno 2021) plentiful. On the other hand, the attraction of the European work/life balance may play a factor.

European students are much less familiar with Chinese cultures and language than Chinese students are with the English language and American and European cultures. This creates a larger barrier to move to a region where the currently perceived academic benefits are few. This may change as awareness of the technological speed of change and available research resources in China increases, creating a stronger pull for both European and American students.

While China is attractive to young hi-tech talent, working weeks are long, giving little opportunity to spend time with family and friends. In Europe, it is not just one's standard of living that is important but also one's quality of life. Development of AI technologies provides hope that both can be achieved through more efficient use of the limited resources available.

Huge efforts have been made to attract successful Chinese AI researchers back to their home country to continue their internationally competitive research and to educate new generations of "home-grown" talent. Both generations of researchers bring with them the competitive, individualistic risk-driven culture learned abroad. Just as in winning in top sport-be it gymnastics, football, or table tennis- two things are essential: individuals with intrinsic potential and motivation and an environment that polishes and hones the required internationally competitive skills. A characteristic of the successful Western research culture is questioning received wisdom, which goes against the grain of Chinese and many other Asian cultures where authority is highly respected.

\section{Global Collaboration on Artificial Intelligence Research and Innovation}

So what are my recommendations in this complex and sometimes contradictory collaboration puzzle?

China is a world leader in AI research, technology, and innovation. As its investment into this field continues to grow, this will only become more pertinent. We therefore cannot ignore the relevance of China in AI research and development, but we can be considered in our approach to collaborations and make informed decisions on a case-by-case basis. Bekkers et al. (2019) provide concrete guidelines on how to approach collaborations.

Questions of international AI collaborations and their effect on the global population are large and daunting. Learning more about your Chinese collaborators and 
colleagues is a much easier and definitely more pleasant task. Read the Lee (2018) book, which gives insights into taking the Silicon Valley start-up culture and transferring it to China while at the same time metamorphosing it to the rules of a new "Wild East." Learn Chinese and visit your colleagues in China.

AI research and innovation is taking place along the New Silk Road. European researchers are already accustomed to global collaborations across different cultures. One of the characteristics of international research culture is the independent exchange of critical feedback, at the same time remaining aware of the implications of the research outcomes. Chinese researchers are developing their own research and innovation strategies, making strategic investments in academic education and research enabling them to become an influential partner on the global stage in research as well as innovation. From both European and Chinese perspectives, AI researchers need to develop a better understanding of the cultures in which we operate. Learning from each other's cultural perspectives is something that our AI systems are not yet able to do for us.

\section{References}

Bekkers F., Oosterveld W. and Verhagen P. (2019) Checklist for Collaboration with Chinese Universities and Other Research Institutions. The Hague Centre for Strategic Studies, January. https://hcss.nl/report/checklist-for-collaboration-with-chinese-universities-and-other-researchinstitutions/

CISTP (2018) China AI Development Report 2018. China Institute for Science and Technology Policy (CISTP) at Tsinghua University. http://www.sppm.tsinghua.edu.cn/eWebEditor/ UploadFile/China_AI_development_report_2018.pdf

Craglia M. et al., 2018. 'Artificial Intelligence: A European Perspective', Publications Office of the European Union, March. https://ec.europa.eu/jrc/en/publication/artificial-intelligence-europeanperspective

Elsevier (2018) Artificial Intelligence: How knowledge is created, transferred, and used. Trends in China, Europe, and the United States. https://www.elsevier.com/research-intelligence/resourcelibrary/ai-report

Hardman L. (2020) Artificial Intelligence along the New Silk Road: Competition or Collaboration? Chapter in: (Van der Wende, 2020). https://ir.cwi.nl/pub/29940

Lee K.-F. (2018) AI Superpowers: China, Silicon Valley, and the New World Order. Houghton Mifflin Co., USA. https://www.aisuperpowers.com

Van der Wende M.C., Kirby W.C., Liu N.C. and Marginson S. (eds.) (2020) China and Europe on the New Silk Road: Connecting Universities across Eurasia. Oxford University Press. https:// global.oup.com/academic/product/china-and-europe-on-the-new-silk-road-9780198853022 
Open Access This chapter is licensed under the terms of the Creative Commons Attribution 4.0 International License (http://creativecommons.org/licenses/by/4.0/), which permits use, sharing, adaptation, distribution and reproduction in any medium or format, as long as you give appropriate credit to the original author(s) and the source, provide a link to the Creative Commons license and indicate if changes were made.

The images or other third party material in this chapter are included in the chapter's Creative Commons license, unless indicated otherwise in a credit line to the material. If material is not included in the chapter's Creative Commons license and your intended use is not permitted by statutory regulation or exceeds the permitted use, you will need to obtain permission directly from the copyright holder. 